\title{
Vulnerabilidad social, aseguramiento $y$ diversificación de riesgos en América Latina y el Caribe
}

\section{Ana Sojo \\ Jefa, Unidad de Desarrollo Social, Sede Subregional de la CEPAL en México asojo@un.org.mx}

La profundidad y magnitud del riesgo social y económico en América Latina exigen, entre otras medidas, políticas de aseguramiento. Las singularidades de los mercados de aseguramiento — como las restricciones del sistema de precios, las características intrínsecas del aseguramiento como bien económico y sus dimensiones de bien público, sus externalidades, la selección de riesgo y sus efectos adversos para la equidad y la eficiencia- justifican consolidar una diversificación de riesgos adecuada y estable, y orientar su financiamiento por el principio de solidaridad, sea mediante cotizaciones obligatorias o bien con cargo al presupuesto nacional. Este artículo hace una revisión crítica de los postulados del denominado manejo del riesgo social que en materia de protección social circunscribe las responsabilidades del Estado al combate de la pobreza mediante redes de protección, que contrapone las políticas focalizadas a las universales, desestima la solidaridad del aseguramiento y hace hincapié en la responsabilidad individual para asegurarse contra riesgos. 


\section{I}

\section{Introducción}

Para encarar la profundidad y magnitud del riesgo social y económico en la región se necesitan diversas políticas públicas. Tras mostrar algunas dimensiones del riesgo, este artículo analiza las singularidades de los mercados de aseguramiento, considerando las restricciones del sistema de precios, las características intrínsecas del aseguramiento como bien económico y sus dimensiones de bien público, sus externalidades, la selección de riesgo y sus efectos adversos para la equidad y la eficiencia. Ellas fundamentan la pertinencia de políticas de aseguramiento que consoliden una diversificación de riesgos adecuada y estable, y cuyo financiamiento se oriente por el principio de solidari- dad, sea mediante cotizaciones obligatorias o con cargo al presupuesto nacional.

Esta perspectiva permite dialogar críticamente con los postulados del manejo del riesgo social (social risk management), que delimita una responsabilidad pública mínima en materia de protección social por dos vías: la de circunscribir las responsabilidades del Estado al combate de la pobreza mediante redes de protección y contraponer las políticas focalizadas a las universales; y en el plano del aseguramiento, la de desestimar y socavar la solidaridad y hacer hincapié en la responsabilidad individual para asegurarse contra los riesgos.

El artículo concluye con algunas reflexiones en torno a la financiación del aseguramiento.

\section{II}

\section{Amplitud y profundidad del riesgo económico y social en la región}

La incertidumbre y el riesgo que enfrentan las personas en la región latinoamericana y del Caribe comprende, entre otros aspectos, los grados de inseguridad económica que acarrean caídas abruptas de los ingresos, el tipo de riesgos idiosincrásicos y la posibilidad de que éstos deriven en riesgos catastróficos, o bien la disminuida capacidad para resistir a las perturbaciones (shocks) una vez que éstas exhiben cierta recurrencia y los activos de los hogares pueden verse progresivamente reducidos. ${ }^{1}$ De allí su relevancia para las políticas públicas.

El actual escenario externo de América Latina y el Caribe es adverso en cuanto a la demanda de sus productos y a la volatilidad de los capitales internacio-

Agradezco los comentarios a versiones previas de este trabajo formulados por Rebeca Grynspan, Juan Carlos Moreno, José Antonio Ocampo y Eugenio Rivera, los que atendí en la medida de mis posibilidades.

${ }^{1}$ A diferencia de los riesgos agregados, comunes o covariados que afectan por igual a la mayoría de determinados grupos, los riesgos idiosincrásicos afectan a individuos o a grupos más específicos de actores económicos. Lo catastrófico alude a la intensidad del riesgo. nales. La región puede caracterizarse en varios sentidos como de alto riesgo social. A pesar de tendencias positivas en algunos países - por ejemplo, la persistente disminución del déficit fiscal, el mantenimiento de equilibrios macroeconómicos y la recuperación o elevación del gasto social-, el crecimiento económico ha sido inestable y con ritmos inferiores a los históricos. En comparaciones internacionales, la alta volatilidad del PIB de la región duplica la de los países industriales y la volatilidad del consumo de los hogares es aun mayor, y ha aumentado desde la década de 1980 (De Ferranti, Perry y otros, 2000). ${ }^{2}$

La vulnerabilidad social se manifiesta en varios aspectos. En muchos países resaltan los altos niveles de pobreza por encima de la media; la reducción gradual de la pobreza lograda en los primeros siete años

\footnotetext{
2 Volatilidad del PIB medida de acuerdo a la desviación estándar de la mediana respecto del crecimiento real del PIB, y volatilidad del consumo de los hogares medida como la desviación estándar del crecimiento del consumo de los hogares (De Ferranti, Perry y otros, 2000, p. 15).
} 
del decenio de 1990 se vio frenada posteriormente. Con pocas excepciones, los indicadores distributivos se han deteriorado. Los mercados de trabajo se han debilitado: ha aumentado el trabajo asalariado no permanente, la cantidad de trabajadores sin seguridad social y el empleo de baja calidad. Sectores medios han visto reducidos sus ingresos o su participación en el ingreso, de modo que no sólo los pobres e indigentes sufren por la volatilidad de la región y por las tendencias a la concentración del ingreso.

Un vasto contingente que no es pobre según sus ingresos es, sin embargo, vulnerable. En muchos países, casi un quinto de los hogares tiene ingresos per cápita que representan de 1,25 a 2 líneas de pobreza, y en un porcentaje de hogares que oscila entre el $7 \%$ y el $11 \%$ los ingresos sólo superan un $25 \%$ de la línea de pobreza. Al respecto se advierten dos tendencias para un número semejante de países: o tales estratos aumentan, o bien se reducen a lo largo de la década de 1990, aunque en forma no muy significativa, salvo por las notables reducciones en Uruguay antes de la reciente crisis financiera (cuadro 1).

Sectores que pueden denominarse "medios bajos" de las zonas urbanas - es decir, el 30\% del total de los hogares contiguo al $40 \%$ más pobre- han visto caer en muchos países su participación en el ingreso total a lo largo del decenio de 1990, a veces en proporciones semejantes a las sufridas por el $40 \%$ más pobre de la población (cuadro 2).

También es significativo que en países donde disminuye el número de hogares pobres e indigentes se incrementen los hogares adyacentes a la línea de pobreza, como sucede en Bolivia, Costa Rica, Guatemala, Panamá y Paraguay (cuadro 2). Cuando un porcentaje apreciable de hogares está sujeto a variaciones bruscas de sus ingresos en el corto plazo, quienes bordean el umbral de pobreza pueden ser los más afectados. ${ }^{3}$

En algunos casos, los efectos benéficos de la estabilización de precios en los ingresos de los hogares son aminorados por patrones de inestabilidad laboral, que se reflejan en el desempleo y en el incremento de puestos precarios (Beccaria, 2001). ${ }^{4}$

Las probabilidades de que las perturbaciones del ingreso afecten a los hogares pobres y a los de ingre-

\footnotetext{
${ }^{3}$ Sobre el bienio 1991-1992, una agrupación tipo panel de la muestra de la encuesta de hogares en el Gran Buenos Aires determinó que los movimientos desde y hacia la pobreza fueron más frecuentes entre los hogares en el umbral de la línea de pobreza (Minujin y López, 1993).

${ }^{4}$ Mediciones realizadas a partir de paneles de datos construidos con información de las encuestas de hogares.
}

sos medios han sido, en algunos casos, semejantes. Los efectos intergeneracionales de las estrategias de los sectores medios frente a esas perturbaciones, considerando su recurrencia, pueden poner en entredicho la propia constitución y permanencia de estos sectores: las estrategias que desarrollen, más allá de su relativa eficacia de corto plazo, pueden tener efectos perniciosos más duraderos que las propias perturbaciones que las gatillaron..$^{5}$ Las más usadas son: vender activos, reducir la inversión en capital humano (sobre todo el segundo quintil), incrementar la participación en la fuerza de trabajo; en estos sectores, aumentar las horas trabajadas o migrar son recursos menos comunes ${ }^{6}$ (Gaviria, 2001, pp. 11-13, 15, 19).

El empobrecimiento de sectores cuya previa inserción formal en el mercado de trabajo les había permitido obtener ingresos adecuados y participación en esquemas de aseguramiento de carácter contributivo, redefine las tareas que respecto de estos sectores debe cumplir el sector público cuando migran hacia prestadores públicos de salud no vinculados a esquemas contributivos, incrementan la demanda de educación pública, o amplían la necesidad de programas destinados a retener a los estudiantes en el sistema educativo. $^{7}$

Por su parte, en el marco de la apertura comercial, los rezagos en materia de calificación de los recursos humanos y las restricciones para la difusión del progreso técnico han ampliado las diferencias de ingreso entre los calificados y los no calificados. Hacia el 2000, en Centroamérica, los ingresos medios de quienes tienen nueve años de educación o más duplican o cuadruplican los de los no calificados. ${ }^{8}$

El manejo del riesgo en sociedades orientadas al mercado implica nuevas responsabilidades públicas (Rodrik, 2001), y en América Latina y el Caribe muchas veces se parte de sendos rezagos en desarrollo social. El riesgo económico y social que enfrentan las personas ante la severidad y frecuencia de las perturbaciones está condicionado por variables económicas muy agregadas, y por el desarrollo social de los países en el

\footnotetext{
${ }^{5}$ Encuesta específica del BID sobre la respuesta de los hogares a las perturbaciones del ingreso, realizada en el 2000 en Colombia, Ecuador, Guatemala, Honduras, Nicaragua, Paraguay y Venezuela, con una muestra de cerca de mil hogares en cada país (Gaviria, 2001). ${ }^{6}$ Aunque la migración ha sido un recurso importante en el último tiempo en Argentina.

${ }^{7}$ Véase Kessler, varios trabajos sin fecha citados en la bibliografía, y Feijóo (2001).

${ }^{8}$ Según tabulados especiales efectuados por la CEPAL sobre la base de encuestas de hogares de los países alrededor del año 2000.
} 
CUADRO 1

América Latina (17 países): Distribución de los hogares según tramos de ingreso per cápita, en términos del valor de la línea de pobreza, zonas urbanas, 1990-1999

\begin{tabular}{|c|c|c|c|c|c|c|c|c|c|}
\hline \multirow[b]{2}{*}{ País } & \multirow[t]{2}{*}{ Año } & \multicolumn{8}{|c|}{ Tramos de ingreso per cápita, en términos del valor de la línea de pobreza } \\
\hline & & $\begin{array}{c}0 \text { a } 0,5 \\
\text { (Indigentes) }\end{array}$ & 0,5 a 0,9 & 0,9 a 1,0 & $\begin{array}{l}0,0 \text { a } 1,0 \\
\text { (Pobres) }\end{array}$ & 1,0 a 1,25 & 1,25 a 2,0 & 2,0 a 3,0 & Más de 3,0 \\
\hline Argentina & 1990 & 3,5 & 10,6 & 2,1 & 16,2 & 7,3 & 22,5 & 18,7 & 35,3 \\
\hline \multirow[t]{3}{*}{ (Gran Buenos Aires) } & 1994 & 1,5 & 6,6 & 2,1 & 10,2 & 7,4 & 16,7 & 19,0 & 46,7 \\
\hline & 1997 & 3,3 & 7,0 & 2,8 & 13,1 & 7,2 & 19,0 & 17,5 & 43,2 \\
\hline & 1999 & 3,1 & 8,5 & 1,6 & 13,2 & 6,2 & 19,1 & 17,8 & 43,9 \\
\hline \multirow[t]{4}{*}{ Bolivia } & 1989 & 22,1 & 23,1 & 4,1 & 49,3 & 9,0 & 16,4 & 10,6 & 14,5 \\
\hline & 1994 & 16,9 & 24,3 & 4,6 & 45,8 & 9,8 & 19,3 & 10,2 & 14,9 \\
\hline & 1997 & 19,2 & 22,6 & 5,1 & 46,8 & 9,7 & 17,2 & 11,2 & 15,2 \\
\hline & 1999 & 16,4 & 20,8 & 5,1 & 42,3 & 10,8 & 18,5 & 11,4 & 17,0 \\
\hline \multirow[t]{4}{*}{ Brasil $^{\mathrm{a}}$} & 1990 & 14,8 & 17,3 & 3,7 & 35,8 & 8,3 & 16,6 & 12,3 & 27,1 \\
\hline & 1993 & 13,5 & 16,0 & 3,8 & 33,3 & 8,5 & 19,0 & 13,3 & 26,0 \\
\hline & 1996 & 9,7 & 11,9 & 3,1 & 24,6 & 7,3 & 17,5 & 15,5 & 35,1 \\
\hline & 1999 & 9,9 & 13,1 & 3,4 & 26,4 & 8,0 & 18,1 & 15,3 & 32,3 \\
\hline \multirow[t]{4}{*}{ Chile } & 1990 & 10,2 & 18,5 & 4,5 & 33,2 & 9,5 & 20,3 & 14,3 & 22,7 \\
\hline & 1994 & 5,9 & 13,3 & 3,6 & 22,8 & 8,5 & 20,7 & 16,6 & 31,4 \\
\hline & 1996 & 4,6 & 11,8 & 3,4 & 19,8 & 8,5 & 20,5 & 17,2 & 34,1 \\
\hline & 1998 & 4,4 & 10,4 & 3,0 & 17,8 & 7,7 & 20,0 & 17,7 & 36,7 \\
\hline \multirow[t]{3}{*}{ Colombia $^{b}$} & 1994 & 16,2 & 20,3 & 4,1 & 40,6 & 9,1 & 18,2 & 12,6 & 19,5 \\
\hline & 1997 & 14,6 & 20,3 & 4,5 & 39,5 & 9,6 & 18,9 & 12,6 & 19,4 \\
\hline & 1999 & 18,7 & 21,5 & 4,4 & 44,6 & 9,5 & 17,7 & 10,8 & 17,4 \\
\hline \multirow[t]{4}{*}{ Costa Rica } & 1990 & 7,3 & 11,2 & 3,7 & 22,2 & 7,9 & 21,9 & 20,2 & 27,9 \\
\hline & 1994 & 5,7 & 9,1 & 3,4 & 18,2 & 7,9 & 20,4 & 20,7 & 32,9 \\
\hline & 1997 & 5,2 & 9,0 & 2,8 & 17,0 & 8,1 & 20,5 & 20,3 & 34,0 \\
\hline & 1999 & 5,4 & 7,9 & 2,3 & 15,6 & 8,5 & 19,3 & 17,7 & 38,8 \\
\hline \multirow[t]{4}{*}{ Ecuador } & 1990 & 22,6 & 28,1 & 5,2 & 55,8 & 10,5 & 16,7 & 8,8 & 8,2 \\
\hline & 1994 & 22,4 & 24,7 & 5,2 & 52,3 & 10,1 & 19,1 & 9,1 & 9,4 \\
\hline & 1997 & 18,6 & 25,6 & 5,6 & 49,8 & 10,0 & 19,4 & 10,7 & 10,0 \\
\hline & 1999 & 27,2 & 25,5 & 5,3 & 58,0 & 7,9 & 16,1 & 7,9 & 10,1 \\
\hline \multirow[t]{3}{*}{ El Salvador } & 1995 & 12,5 & 22,4 & 5,1 & 40,0 & 12,0 & 22,0 & 12,8 & 13,3 \\
\hline & 1997 & 12,0 & 21,8 & 4,8 & 38,6 & 11,0 & 21,8 & 13,6 & 15,0 \\
\hline & 1999 & 11,1 & 19,0 & 3,9 & 34,0 & 9,8 & 21,7 & 15,4 & 19,1 \\
\hline \multirow[t]{2}{*}{ Guatemala } & 1989 & 22,9 & 21,0 & 4,3 & 48,2 & 8,5 & 17,3 & 11,0 & 15,0 \\
\hline & 1998 & 12,9 & 21,8 & 4,2 & 38,9 & 10,9 & 20,0 & 12,5 & 17,8 \\
\hline \multirow[t]{4}{*}{ Honduras } & 1990 & 38,0 & 22,7 & 3,8 & 64,5 & 8,2 & 12,0 & 6,5 & 8,8 \\
\hline & 1994 & 40,8 & 24,5 & 4,3 & 69,6 & 7,6 & 12,0 & 5,1 & 5,8 \\
\hline & 1997 & 36,8 & 26,0 & 4,2 & 67,0 & 8,2 & 12,5 & 5,9 & 6,4 \\
\hline & 1999 & 37,7 & 24,4 & 4,2 & 66,2 & 8,2 & 12,9 & 6,4 & 7,0 \\
\hline \multirow[t]{4}{*}{ México } & 1989 & 9,3 & 19,8 & 4,8 & 33,9 & 11,0 & 22,3 & 13,1 & 19,8 \\
\hline & 1994 & 6,2 & 18,2 & 4,6 & 29,0 & 10,8 & 21,8 & 14,4 & 24,0 \\
\hline & 1996 & 10,0 & 22,2 & 5,3 & 37,5 & 10,7 & 21,3 & 12,4 & 18,1 \\
\hline & 1998 & 6,9 & 19,1 & 5,1 & 31,1 & 11,0 & 22,0 & 15,3 & 20,6 \\
\hline \multirow[t]{2}{*}{ Nicaragua } & 1993 & 32,2 & 23,5 & 4,6 & 60,3 & 8,2 & 15,7 & 6,9 & 9,0 \\
\hline & 1998 & 30,7 & 24,1 & 4,5 & 59,3 & 8,6 & 15,8 & 7,6 & 8,7 \\
\hline
\end{tabular}

(Continúa en la página siguiente) 
Cuadro 1 (continuación)

\begin{tabular}{|c|c|c|c|c|c|c|c|c|c|}
\hline \multirow[b]{2}{*}{ País } & \multirow[t]{2}{*}{ Año } & \multicolumn{8}{|c|}{ Tramos de ingreso per cápita, en términos del valor de la línea de pobreza } \\
\hline & & $\begin{array}{c}0 \text { a } 0,5 \\
\text { (Indigentes) }\end{array}$ & 0,5 a 0,9 & 0,9 a 1,0 & $\begin{array}{l}0,0 \text { a } 1,0 \\
\text { (Pobres) }\end{array}$ & 1,0 a 1,25 & 1,25 a 2,0 & 2,0 a 3,0 & Más de 3,0 \\
\hline \multirow[t]{4}{*}{ Panamá } & 1991 & 13,9 & 15,5 & 4,2 & 33,6 & 8,5 & 17,0 & 13,7 & 27,2 \\
\hline & 1994 & 8,7 & 13,2 & 3,4 & 25,3 & 7,7 & 19,2 & 16,5 & 31,3 \\
\hline & 1997 & 8,6 & 12,2 & 3,7 & 24,6 & 7,5 & 18,8 & 15,4 & 33,7 \\
\hline & 1999 & 6,6 & 10,9 & 3,3 & 20,8 & 7,6 & 18,2 & 16,2 & 37,1 \\
\hline \multirow[t]{4}{*}{ Paraguay (Asunción) } & 1990 & 10,4 & 21,7 & 4,7 & 36,8 & 13,6 & 19,6 & 14,2 & 15,9 \\
\hline & 1994 & 9,5 & 20,9 & 5,0 & 35,4 & 11,6 & 20,4 & 13,4 & 19,3 \\
\hline & 1996 & 8,0 & 19,2 & 6,4 & 33,5 & 11,3 & 22,2 & 13,5 & 19,5 \\
\hline & 1999 & 6,9 & 20,7 & 5,2 & 32,8 & 11,9 & 19,9 & 16,2 & 19,2 \\
\hline República Dominicana & 1997 & 11,0 & 16,6 & 4,0 & 31,6 & 10,4 & 21,5 & 15,6 & 21,0 \\
\hline \multirow[t]{4}{*}{ Uruguay } & 1990 & 2,0 & 7,0 & 2,8 & 11,8 & 7,1 & 22,7 & 23,1 & 35,3 \\
\hline & 1994 & 1,1 & 3,4 & 1,3 & 5,8 & 3,6 & 15,4 & 23,2 & 52,0 \\
\hline & 1997 & 0,9 & 3,5 & 1,4 & 5,7 & 4,0 & 15,2 & 21,4 & 53,8 \\
\hline & 1999 & 0,9 & 3,4 & 1,4 & 5,7 & 3,6 & 13,5 & 20,5 & 56,9 \\
\hline \multirow[t]{4}{*}{ Venezuela $^{\mathrm{c}}$} & 1990 & 10,9 & 17,5 & 5,0 & 33,4 & 10,9 & 21,5 & 14,8 & 19,4 \\
\hline & 1994 & 13,5 & 22,0 & 5,4 & 40,9 & 10,4 & 21,4 & 12,9 & 14,4 \\
\hline & 1997 & 16,5 & 21,2 & 4,6 & 42,3 & 10,6 & 19,3 & 11,5 & 16,3 \\
\hline & 1999 & 18,8 & 21,0 & 4,2 & 44,0 & 10,3 & 19,5 & 11,5 & 14,8 \\
\hline
\end{tabular}

Fuente: CEPAL, sobre la base de tabulaciones especiales de encuestas de hogares de los respectivos países.

a En Brasil, para calcular la línea de pobreza se multiplicó el valor de la línea de indigencia por un coeficiente variable y no fijo (2,0), como en el resto de los casos.

b A partir de 1993, se amplió la cobertura geográfica de la encuesta hasta abarcar prácticamente la totalidad de la población urbana del país. Hasta 1992, la encuesta cubría alrededor de la mitad de dicha población, salvo en 1991, año en que se realizó una encuesta de carácter nacional.

c A partir de 1997 el diseño muestral de la encuesta no permite el desglosamiento urbano-rural. Por lo tanto, las cifras corresponden al total nacional.

marco de sus sistemas políticos. Las políticas públicas respectivas atañen, por tanto, a muy diversos planos.

En cuanto a las políticas macroeconómicas, es fundamental asegurarse de que ellas sean estables, sustentables y orientadas al crecimiento, y establecer normas estrictas de regulación y supervisión financieras e instrumentos que proporcionen mayor libertad para adoptar políticas anticíclicas con recursos obtenidos en los períodos de crecimiento y euforia financiera (Ocampo, 2001).

Las políticas de desarrollo productivo y relativas al mercado laboral son cruciales por la irradiación de sus efectos. Mediante simulaciones sobre los impactos individuales de las perturbaciones, considerando la diversificación de la estructura productiva y cambios en la productividad, se llega a importantes hallazgos. Respecto de Costa Rica, el aumento de la productividad aparece como una condición necesaria para que el proceso de liberalización comercial tenga un impacto positivo general, y se confirma la relación entre liberalización comercial, aumento de la productividad y reducción de la pobreza (Sauma y Sánchez, 2003, p. 24).

Las políticas de desarrollo productivo están íntimamente ligadas a las de educación y formación profesional, y justamente la depreciación de la calidad educativa y la expansión asimétrica de los sistemas de educación incrementan el riesgo social y los costos del aseguramiento. Esto porque la baja calidad y limitada pertinencia de la educación incide en la inserción laboral futura de las personas, y reduce la calidad del capital humano y su flexibilidad para encarar períodos de cambio.

A pesar de la avanzada etapa de transición demográfica en que se halla la región, persisten en ella síndromes demográficos asociados con la pobreza y la vulnerabilidad: la fecundidad alta prevalece en los estratos bajos y en los grupos con escasa o nula educación, y ha aumentado la fecundidad registrada a los 17 años cumplidos. La elevada fecundidad de las 
CUADRO 2

América Latina (15 países): Nivel y distribución del ingreso de los hogares, zonas urbanas y rurales, ${ }^{a}$ 1990-1999

(En porcentajes)

\begin{tabular}{|c|c|c|c|c|c|c|}
\hline \multirow[b]{2}{*}{ Países } & \multirow[b]{2}{*}{ Años } & \multirow{2}{*}{$\begin{array}{l}\text { Ingreso } \\
\text { medio }^{b}\end{array}$} & \multicolumn{4}{|c|}{ Participación en el ingreso total del: } \\
\hline & & & $\begin{array}{c}40 \% \\
\text { más pobre }\end{array}$ & $\begin{array}{c}30 \% \\
\text { siguiente }\end{array}$ & $\begin{array}{l}20 \% \text { anterior } \\
\text { al } 10 \% \text { más rico }\end{array}$ & $\begin{array}{c}10 \% \\
\text { más rico }\end{array}$ \\
\hline Argentina $^{c}$ & $\begin{array}{l}1990 \\
1997 \\
1999\end{array}$ & $\begin{array}{l}10,6 \\
12,4 \\
12,5\end{array}$ & $\begin{array}{l}14,9 \\
14,9 \\
15,4\end{array}$ & $\begin{array}{l}23,6 \\
22,3 \\
21,6\end{array}$ & $\begin{array}{l}26,7 \\
27,1 \\
26,1\end{array}$ & $\begin{array}{l}34,8 \\
35,8 \\
37,0\end{array}$ \\
\hline Bolivia & $\begin{array}{l}1989^{d} \\
1997 \\
1999\end{array}$ & $\begin{array}{l}7,7 \\
7,2 \\
7,2\end{array}$ & $\begin{array}{l}12,1 \\
13,6 \\
15,2\end{array}$ & $\begin{array}{l}22,0 \\
22,5 \\
24,1\end{array}$ & $\begin{array}{l}27,9 \\
26,9 \\
28,0\end{array}$ & $\begin{array}{l}38,2 \\
37,0 \\
32,7\end{array}$ \\
\hline Brasil & $\begin{array}{l}1990 \\
1996 \\
1999\end{array}$ & $\begin{array}{l}10,4 \\
13,6 \\
12,3\end{array}$ & $\begin{array}{l}10,3 \\
10,5 \\
10,6\end{array}$ & $\begin{array}{l}19,4 \\
18,1 \\
17,7\end{array}$ & $\begin{array}{l}28,5 \\
27,0 \\
26,1\end{array}$ & $\begin{array}{l}41,8 \\
44,3 \\
45,7\end{array}$ \\
\hline Chile & $\begin{array}{l}1990 \\
1996 \\
2000\end{array}$ & $\begin{array}{r}9,4 \\
13,5 \\
14,1\end{array}$ & $\begin{array}{l}13,4 \\
13,4 \\
14,0\end{array}$ & $\begin{array}{l}21,2 \\
20,9 \\
20,9\end{array}$ & $\begin{array}{l}26,2 \\
26,4 \\
25,4\end{array}$ & $\begin{array}{l}39,2 \\
39,4 \\
39,7\end{array}$ \\
\hline Colombia & $\begin{array}{l}1994 \\
1997 \\
1999\end{array}$ & $\begin{array}{l}9,0 \\
8,4 \\
7,3\end{array}$ & $\begin{array}{l}11,6 \\
12,9 \\
12,6\end{array}$ & $\begin{array}{l}20,4 \\
21,4 \\
21,9\end{array}$ & $\begin{array}{l}26,1 \\
26,1 \\
26,6\end{array}$ & $\begin{array}{l}41,9 \\
39,5 \\
38,8\end{array}$ \\
\hline Costa Rica & $\begin{array}{l}1990 \\
1997 \\
1999\end{array}$ & $\begin{array}{r}9,6 \\
10,5 \\
11,9\end{array}$ & $\begin{array}{l}17,8 \\
17,3 \\
16,2\end{array}$ & $\begin{array}{l}28,7 \\
27,6 \\
26,8\end{array}$ & $\begin{array}{l}28,9 \\
28,4 \\
29,9\end{array}$ & $\begin{array}{l}24,6 \\
26,8 \\
27,2\end{array}$ \\
\hline Ecuador & $\begin{array}{l}1990 \\
1997 \\
1999\end{array}$ & $\begin{array}{l}5,5 \\
6,0 \\
5,6\end{array}$ & $\begin{array}{l}17,1 \\
17,0 \\
14,1\end{array}$ & $\begin{array}{l}25,4 \\
24,7 \\
22,8\end{array}$ & $\begin{array}{l}27,0 \\
26,4 \\
26,5\end{array}$ & $\begin{array}{l}30,5 \\
31,9 \\
36,6\end{array}$ \\
\hline El Salvador & $\begin{array}{l}1995 \\
1997 \\
1999\end{array}$ & $\begin{array}{l}6,9 \\
7,1 \\
7,7\end{array}$ & $\begin{array}{l}17,3 \\
17,2 \\
16,3\end{array}$ & $\begin{array}{l}25,1 \\
24,8 \\
25,9\end{array}$ & $\begin{array}{l}25,8 \\
26,9 \\
28,6\end{array}$ & $\begin{array}{l}31,7 \\
31,1 \\
29,2\end{array}$ \\
\hline Guatemala & $\begin{array}{l}1989 \\
1998\end{array}$ & $\begin{array}{l}7,7 \\
8,8\end{array}$ & $\begin{array}{l}12,1 \\
14,7\end{array}$ & $\begin{array}{l}22,6 \\
22,0\end{array}$ & $\begin{array}{l}27,4 \\
26,0\end{array}$ & $\begin{array}{l}37,9 \\
37,5\end{array}$ \\
\hline Honduras & $\begin{array}{l}1990 \\
1997 \\
1999\end{array}$ & $\begin{array}{l}5,5 \\
4,7 \\
4,6\end{array}$ & $\begin{array}{l}12,2 \\
14,3 \\
14,3\end{array}$ & $\begin{array}{l}20,8 \\
22,8 \\
24,0\end{array}$ & $\begin{array}{l}28,1 \\
26,1 \\
27,9\end{array}$ & $\begin{array}{l}38,9 \\
36,8 \\
33,9\end{array}$ \\
\hline México & $\begin{array}{l}1989 \\
1994 \\
1998\end{array}$ & $\begin{array}{l}9,6 \\
9,7 \\
8,6\end{array}$ & $\begin{array}{l}16,3 \\
16,8 \\
17,2\end{array}$ & $\begin{array}{l}22,0 \\
22,8 \\
22,3\end{array}$ & $\begin{array}{l}24,9 \\
26,1 \\
25,7\end{array}$ & $\begin{array}{l}36,9 \\
34,3 \\
34,8\end{array}$ \\
\hline Nicaragua & $\begin{array}{l}1993 \\
1998\end{array}$ & $\begin{array}{l}6,1 \\
6,4\end{array}$ & $\begin{array}{l}12,9 \\
12,3\end{array}$ & $\begin{array}{l}23,6 \\
22,3\end{array}$ & $\begin{array}{l}26,9 \\
26,4\end{array}$ & $\begin{array}{l}36,5 \\
39,1\end{array}$ \\
\hline Panamá & $\begin{array}{l}1991 \\
1997 \\
1999\end{array}$ & $\begin{array}{r}9,5 \\
12,0 \\
12,2\end{array}$ & $\begin{array}{l}13,3 \\
13,3 \\
14,2\end{array}$ & $\begin{array}{l}23,9 \\
22,4 \\
23,9\end{array}$ & $\begin{array}{l}28,6 \\
27,0 \\
26,8\end{array}$ & $\begin{array}{l}34,2 \\
37,3 \\
35,1\end{array}$ \\
\hline Paraguay & $\begin{array}{l}1990^{\mathrm{e}} \\
1996 \\
1999\end{array}$ & $\begin{array}{l}7,7 \\
7,4 \\
7,1\end{array}$ & $\begin{array}{l}18,6 \\
16,7 \\
16,5\end{array}$ & $\begin{array}{l}25,7 \\
24,6 \\
24,9\end{array}$ & $\begin{array}{l}26,9 \\
25,3 \\
25,8\end{array}$ & $\begin{array}{l}28,9 \\
33,4 \\
32,8\end{array}$ \\
\hline Uruguay & $\begin{array}{l}1990 \\
1997 \\
1999\end{array}$ & $\begin{array}{r}9,3 \\
11,2 \\
11,9\end{array}$ & $\begin{array}{l}20,1 \\
22,0 \\
21,6\end{array}$ & $\begin{array}{l}24,6 \\
26,1 \\
25,5\end{array}$ & $\begin{array}{l}24,1 \\
26,1 \\
25,9\end{array}$ & $\begin{array}{l}31,2 \\
25,8 \\
27,0\end{array}$ \\
\hline
\end{tabular}

Fuente: CEPAL, sobre la base de tabulaciones especiales de las encuestas de hogares de los respectivos países.

a Hogares de cada zona del país ordenados según su ingreso per cápita.

b Ingreso medio mensual de los hogares, en múltiplos de la línea de pobreza per cápita.

c Gran Buenos Aires.

d Ocho ciudades principales y El Alto.

e Área metropolitana de Asunción. 
mujeres jóvenes (20-29 años) revela una persistente contraposición entre la carga de la crianza y la acumulación de activos educacionales o de experiencia laboral (Rodríguez, 2003). Más adelante nos referiremos a la prevalencia de una transición epidemiológica polarizada.
Para enfrentar los riesgos económicos y sociales aludidos son necesarias también políticas de aseguramiento, cuyas formas de financiación deben contemplar la complejidad de estos mercados. Acudiendo a la literatura sobre aseguramiento, abordaremos seguidamente este tema.

\title{
III
}

\section{El riesgo social y los desafíos del aseguramiento}

\begin{abstract}
El Estado de bienestar es mucho más que una red de protección social; se justifica no sólo por cualesquiera fines redistributivos que uno pueda tener (o no tener), sino también porque hace cosas que los mercados privados, por razones técnicas, de ninguna manera harían, o harían con ineficiencia. Necesitamos un Estado de bienestar por cierto tipo de razones de eficiencia y lo seguiremos necesitando aun cuando todos los problemas distributivos se hubiesen resuelto (Barr, 1993).
\end{abstract}

La acción del Estado o la participación obligatoria en una mancomunación (pool) de riesgos es pertinente no sólo cuando los mecanismos de mercado no existen, colapsan o son disfuncionales, puesto que las asimetrías de información y las fallas de mercado son inherentes a los mercados de aseguramiento, y no situaciones excepcionales. ${ }^{9}$ En esos términos, la acción pública regulatoria, el aseguramiento público, o el aseguramiento social con aseguradores privados pero con mecanismos de financiamiento obligatorio y regulaciones que garanticen la diversificación del riesgo, permiten enfrentar la selección del riesgo e incrementar la eficiencia de estos mercados, al propiciar la estabilidad del aseguramiento. Cuando se opta por el financiamiento solidario, los objetivos, además, son redistributivos, y es posible establecer subsidios cruzados entre estratos de ingreso, grupos etarios, de riesgo, $\mathrm{u}$ otros.

Las asimetrías de información y fallas de mercado del aseguramiento están relacionadas con múltiples

\footnotetext{
${ }^{9}$ Así se advierte en afirmaciones como la siguiente: "Las conductas de riesgo moral no son un problema insuperable si el aseguramiento social imita al mercado tanto como sea posible" (De Ferranti, Perry y otros, 2000, p. 42; cursivas propias). En tanto que una vasta literatura, inaugurada por Arrow (1963), encara justamente la presencia de las conductas de riesgo moral en el mercado del aseguramiento.
}

elementos, entre los que sobresalen: la selección adversa; las conductas de riesgo moral; las complejidades y opacidades que la naturaleza y la calidad del producto - es decir, el aseguramiento y las prestaciones en sus diversas variantes - ofrecen al consumidor; la complejidad y heterogeneidad del producto asociado al aseguramiento (como en el caso de las prestaciones de salud); las externalidades del consumo; y el subconsumo por incapacidad de pagar las primas de un seguro privado debido a bajos ingresos o a enfermedades crónicas o congénitas, en cuyo caso no se tiene acceso al aseguramiento aunque el mercado exista.

Naturalmente, la cantidad y calidad de la protección social que puede darse mediante contribuciones obligatorias, con cargo a impuestos generales, o combinando ambas cosas, está sujeta al nivel de desarrollo económico que la hace posible, como también a los pactos fiscales vigentes que encarnan también acuerdos políticos y sociales respecto del nivel de bienestar que cabe garantizar a los ciudadanos (CEPAL, 2000).

Las políticas focalizadas estrictamente en los sectores pobres no resultan suficientes, y en lo que se refiere al aseguramiento, no permiten una diferenciación de riesgo adecuada y estable, ya que el subconsumo en materia de aseguramiento afecta a amplios sectores sociales, no sólo a los pobres. De allí la necesidad de establecer políticas de aseguramiento, que 
consoliden la diversificación de riesgos y la solidaridad en los diferentes mercados: el mercado de la salud, el mercado de trabajo, de las pensiones, y otros.

\section{El aseguramiento en el mercado, las primas y el valor social}

Para iniciar el análisis conviene, en primer término, partir de una definición de aseguramiento. Se entiende por aseguramiento el conjunto de transacciones mediante las cuales el pago de un monto determinado permite recibir otro pago si ocurren ciertos eventos. Dado que cada individuo está expuesto a un determinado conjunto de riesgos, obtiene un beneficio al reducir su riesgo agregado mediante la diversificación. El aseguramiento en el mercado permite trasladar riesgos a una agencia que pueda enfrentarlos merced a su capacidad de diversificación y posibilita así que los individuos encaren actividades riesgosas (Arrow, 2000, pp. 220-229). $\mathrm{El}$ aseguramiento permite reducir la brecha entre los niveles efectivos de dotación de ingresos y los niveles deseados en diferentes circunstancias, y guarda analogía con el ahorro, que disminuye la brecha entre los niveles de dotación y de consumo a lo largo de diferentes momentos en el tiempo (Ehrlich y Becker, 2000, p. 171).

Como situación ideal, todos querrían encontrar un mercado en el cual asegurarse libremente contra cualquier evento económicamente relevante, a precios determinados por el equilibrio de la relación entre oferta y demanda. La realidad histórica dista de ello; no todas las transferencias de riesgos que serían deseables se pueden lograr por medio del mercado, lo que origina problemas que la sociedad enfrenta de diversas maneras. Como el sistema de precios es incapaz de manejar adecuadamente algunos riesgos, se limita su uso, con lo cual el aseguramiento de mercado se restringe tanto en su cobertura como en su monto. Por ejemplo, los límites en el aseguramiento privado de la salud acarrean desprotección para gastos médicos elevados, precisamente aquellos contra los cuales resultaría muy atractivo asegurarse (Arrow, 2000, pp. 220-229).

Los mercados de aseguramiento a veces no existen en la región o no están desarrollados adecuadamente. Pero además, por la relación precios/ingresos y en países con una concentración de ingresos particularmente alta, la necesidad de aseguramiento de la población no puede traducirse en una demanda efectiva cuando las remuneraciones son bajas o se sufren episodios de desempleo, factores todos que llevan al subconsumo de aseguramiento.
Por otra parte, más allá de las características intrínsecas del aseguramiento como bien económico y de las consecuencias que pueden derivarse de ellas, es necesario tener presente que cuando los valores de justicia y equidad se vinculan con los de eficacia y eficiencia se establecen determinados bienes y servicios como derechos relacionados con esos valores. Esto ocurre dentro de procesos políticos: en gobiernos representativos se generan acuerdos respecto de los ámbitos de acción y de los recursos necesarios para satisfacer aspiraciones sociales o para atender condiciones sociales agregadas que, en el caso que nos concierne, pueden referirse al aseguramiento (Moore, 2001, p. 30).

Tanto el nivel como la distribución de la producción del valor social, que expresa las preferencias combinadas de los ciudadanos en un sistema político en cuanto a satisfacer una condición social agregada y que implica determinadas obligaciones sociales, son establecidos por ciudadanos que actúan en el ámbito de la política más que por consumidores que actúan en el mercado. En ese sentido, en términos de decisión, el diálogo político es a la esfera de lo público lo que el mercado es a los esfuerzos privados, con la singularidad de que tiene un carácter representativo, apela a lo que es deseable para la sociedad como un todo, e implica discusión de principios y valores. Los recursos necesarios para solucionar problemas considerados públicos son escasos, al igual que la autoridad pública o la obligación moral con ellos vinculadas. Así, la política es la respuesta que la democracia liberal ha dado a la cuestión, analíticamente no resuelta, de qué cosas deben producirse para propósitos colectivos con recursos públicos. El caso del aseguramiento atañe a recursos fiscales y a los sistemas de cotización obligatorios con diferenciación de riesgo (Moore, 2001, pp. 41, 43, 44 y 49 ).

El hecho de que se requiere financiamiento para encarar los desafíos de la equidad y de las sinergias entre desarrollo social y desarrollo económico pone sobre el tapete la necesidad de establecer en los países pactos fiscales que determinen niveles de protección, según las posibilidades económicas y los acuerdos políticos (CEPAL, 2000).

Debe tenerse presente, además, la singularidad de algunos bienes en relación con el aseguramiento. Puede suponerse que todos los productos sujetos a pérdida pueden ser valorados en los mercados pertinentes y que los seguros permiten reemplazarlos parcial o totalmente mediante compensaciones monetarias (es el caso, por ejemplo, de un auto que sufre un accidente de tránsito). Sin embargo, hay cosas que no tienen sustitu- 
tos de mercado adecuados, como la pérdida de la vida, o la pérdida de la buena salud, con componentes no monetarios como el dolor, la discapacidad o el sufrimiento (Dionne y Harrington, 2000, p. 12). Al no haber sustitutos perfectos de algunas fuentes permanentes de beneficio, como la buena salud, no existen en sentido estricto mercados de ellos, aunque los individuos puedan imputarles determinados valores monetarios. Tal valoración puede variar y esto se considera en la teoría del comportamiento ante los riesgos; por ejemplo, porque puede conducir a que tienda a ser menor la cantidad de aseguramiento que se compre en el mercado (Cook y Graham, 2000, pp. 207 y 214) y, por lo tanto, a que haya un subaseguramiento que acarree costos individuales y sociales. En esta perspectiva, cobra sentido el aseguramiento obligatorio frente a comportamientos de polizón (free-rider).

En el ámbito de la salud es importante tener en cuenta que las políticas de aseguramiento, los sistemas de salud desarrollados, las políticas preventivas en materia de salud y una cultura de la salud son todos factores que pueden impedir o prevenir una pérdida definitiva de la buena salud. De allí la importancia del aseguramiento, que puede permitir el acceso a servicios preventivos y curativos en el momento oportuno. Un aseguramiento adecuado permite encarar condiciones de morbilidad reversibles y que tienen sustitutos de mercado mediante precios de restauración de la salud que el aseguramiento puede cubrir, mientras que la desprotección puede conducir a situaciones de morbilidad irreversibles que no tienen sustitutos de mercado para encararlas.

\section{Aseguramiento, bienes públicos y externa- lidades}

Para calibrar la relevancia del aseguramiento en la región hay que considerar las dimensiones de bien público, o de combinación de elementos de bien público y de bien privado, que él pueda tener, o bien sus externalidades. Para los bienes públicos puros la teoría ha establecido un criterio exigente: la no rivalidad en el consumo, es decir, la total ausencia de conflicto entre el consumo que realizan diferentes individuos. Siendo indeseable la exclusión de individuos del acceso a estos bienes mediante los precios, ellos deben ser provistos a través de otras fuentes de ingreso. El desempeño del mercado dependerá en forma crucial de las características del bien público en cuanto a posibilidades de exclusión, número de individuos que disfrutan de él, existencia de amplios beneficios a los con- sumidores directos, economías de escala en su producción, y marco legal e institucional en el cual tienen lugar las transacciones. Dado este complejo de factores, se afirma que poco puede generalizarse más allá de aseverar que los mercados privados tienden a subproveer bienes públicos y a sobreproveer males públicos. Muchos de los servicios a cargo de los gobiernos, por el lado de la provisión o del financiamiento, combinan elementos públicos y privados. Las decisiones políticas respecto de la provisión y financiamiento de bienes públicos tienen sendos impactos distributivos y se mezclan con consideraciones de eficiencia económica; de allí que acertadamente se reconozca la importancia de comprender mejor estos procesos, incorporando variables políticas en los modelos normativos de oferta de bienes públicos (Oakland, 1991, pp. 492, 509 y 533).

El producto social neto se acrecienta cuando otros beneficios exceden los obtenidos directamente por las personas mediante una transacción, por lo cual se requiere una subvención que cubra las externalidades no reflejadas en la demanda del mercado; los instrumentos fiscales son mecanismos que permiten reconocer externalidades (Musgrave, 1985, p. 11).

Con este trasfondo cabe señalar por qué es importante que el aseguramiento tenga objetivos de redistribución, y apunte a la diversificación estable de los riesgos mediante contribuciones obligatorias o el financiamiento público de los indigentes.

Dos importantes consideraciones relativas a la incidencia social del bienestar individual justifican que la sociedad, mediante el presupuesto público, garantice el acceso de los ciudadanos a determinados servicios sociales en tanto bienes de mérito. Es preciso entender que, dadas las externalidades del bienestar individual, existe una estrecha relación entre el bienestar individual y el bienestar social. También que la sociedad y los individuos no pueden abdicar voluntariamente de los bienes públicos o cuasi públicos, pues éstos tienen como característica singular la imposibilidad de dejar de consumirlos, o al menos de consumir sus externalidades, salvo que se abandone la comunidad que los provee (Hirschman, 1970). Esto se expresa en múltiples y diversas dimensiones: la vida privada de los ciudadanos, la seguridad ciudadana y la competitividad de los países en un mundo abierto y globalizado están afectadas, de hecho, por la calidad de la educación y de la salud públicas, o por el grado de integración social.

Es pertinente también aludir tanto al entramado microeconómico de algunas dimensiones del aseguramiento como a las repercusiones macroeconómicas que 
puede acarrear. En un contexto de salarios flexibles, el costo de los beneficios provistos por el empleador se traslada parcialmente al trabajador mediante salarios menores; luego, si los trabajadores no valoran tanto aquellos beneficios como esta disminución, pueden buscar trabajo en el sector desregulado, donde la remuneración es totalmente monetaria. Esto puede ocurrir cuando la provisión de la seguridad social o de los beneficios de salud son muy ineficientes o los vínculos entre beneficios y contribuciones muy débiles, o bien si algún miembro de la familia ya inserto en el sector formal provee una cobertura familiar. Junto a las asimetrías de información y a los débiles derechos de propiedad, la baja eficiencia y calidad de los sistemas de seguridad social se han señalado asimismo como elementos que propician el aislamiento de las microempresas respecto del mercado (De Ferranti, Perry y otros, 2002, recuadro 5.5 y p. 145).

Vistas desde el ángulo de este artículo, tales conclusiones son sugerentes para argumentar precisamente a favor de reformas en el aseguramiento, si consideramos que las carencias en materia de seguridad social o los beneficios de salud precarios son externalidades negativas, que no crean incentivos adecuados para profundizar los mercados laborales.

En el mismo ámbito de externalidades, cabe también tener en cuenta que las estrategias de los hogares pobres y de medianos ingresos para amortiguar los choques - cuando la protección social es precaria y los mercados de aseguramiento poco desarrollados- pueden resultar eficaces en algunos casos para proteger los niveles de consumo, pero no son necesariamente muy productivas. En ese sentido, el aseguramiento precario o inexistente afecta tanto la asignación como la disponibilidad de recursos de los hogares. ${ }^{10} \mathrm{Como}$ complemento, es útil reflexionar en ese contexto sobre las repercusiones positivas que puede tener el aseguramiento en el crecimiento económico: si suponemos que el ahorro genera crecimiento y que existe un estrecho vínculo entre el ahorro de los hogares y el ahorro nacional, es interesante considerar el aseguramiento como determinante del ahorro de los hogares, con repercusiones macroeconómicas. Si cada individuo no es una isla, el seguro social es uno de los mecanismos que, al diversificar los riesgos, actúa como emparejador y estabilizador del consumo frente a sus fluctuaciones, en reemplazo de estrategias individua-

\footnotetext{
${ }^{10}$ Esta es una reformulación de planteamientos realizados por Baulch y Hoddinott (2000), pp. 19-21.
}

les y autárquicas de ahorro y desahorro a lo largo del tiempo (Deaton, 1997, pp. 335-400).

\section{Equidad, selección de riesgos y financiamiento solidario}

No debe sobredimensionarse la capacidad de enfrentar riesgos idiosincrásicos mediante instrumentos de riesgo informales o de mercado: sin una adecuada diversificación del riesgo, tienen lugar exclusiones y desigualdades.

En ausencia de regulación y de restricciones a las primas, la norma en los mercados competitivos es que los planes de salud establezcan primas ajustadas a los riesgos individuales: esto es lo que se denomina el principio de equivalencia. Los planes varían según los riesgos observables y se diseñan paquetes de beneficios para atraer determinados tipos de riesgos. Cuando los costos del riesgo son muy altos, esto puede conducir a que los planes excluyan de la cobertura algunas condiciones médicas preexistentes o no establezcan contratos con individuos de alto riesgo (Van de Ven y Ellis, 2000, p. 759).

Para conciliar la eficiencia con los criterios de justicia y equidad, son cruciales mecanismos de ajuste de riesgo que permitan una diversificación de riesgos amplia. Debido a las imperfecciones de estos mecanismos, siempre existen incentivos para que haya selección de riesgos en los planes de salud de mercados competitivos: cuanto mejores sean los subsidios explícitos para riesgos relevantes, menor será la transacción entre los objetivos de eficiencia y de justicia. Los sistemas de subsidios ajustados al riesgo pretenden dar subsidios explícitos a individuos de alto riesgo; por su parte, la regulación del diseño de planes y las restricciones a la variación de las contribuciones individuales pretende que haya subsidios implícitos de los individuos de bajo riesgo a los de alto riesgo (Van de Ven y Ellis, 2000, pp. 762-763). Debido a las asimetrías de información, los costos de entrada o de transacción son elevados y pueden conducir a que los aseguradores fijen altas pólizas (Belli, 2001, p. 21).

En cuanto a las pensiones, en los sistemas de pensiones que consideran parcial o totalmente la modalidad de capitalización individual, el riesgo es asumido individualmente y diferenciado por sexo. Los sesgos contra las mujeres de estos sistemas han generado consecuencias no esperadas, especialmente en lo que respecta al bienestar de las mujeres y sus hijos y a la economía familiar. 
Varios argumentos fundamentan la necesidad de redistribuir riesgos. En primer lugar, consideraciones de equidad, para garantizar que los viejos, los enfermos crónicos y otros grupos de alto riesgo tengan una cobertura justa. En segundo lugar, un argumento vinculado al ciclo de vida: los jóvenes o quienes tienen un bajo riesgo en salud aceptan pagar más que lo que consumen, ya que en el futuro podrán beneficiarse a su vez de una cobertura subsidiada. Incluso en un contexto estático, podrán estar anuentes al subsidio, como un medio para acercarse a un grado de cobertura más cercano a su preferencia de un contrato con cobertura total (Belli, 2001, p. 18; CEPAL, 2000).

Los contratos anuales y que varían de acuerdo con el estatus de salud observable (por ejemplo, mediante el denominado experience rating, que considera nuevos cuadros de morbilidad o enfermedades preexistentes) impiden el aseguramiento intertemporal, es decir, el derecho a comprar coberturas futuras de salud a costos medios aun cuando enfermen hoy (Cutler y Zeckhauser, 2000, p. 564). Los beneficios intergeneracionales o entre personas con condiciones diversas de salud, mirados en una perspectiva dinámica, representan también beneficios individuales intertemporales de magnitud diversa. Además, el ahorro obligatorio en estado sano para estados de enfermedad aguda o crónica tiene efectos microeconómicos y macroeconómicos positivos, ya que acrecienta el ahorro de los hogares y empareja su consumo.

El financiamiento solidario del aseguramiento en salud tiene objetivos redistributivos, ya que permite establecer subsidios cruzados entre estratos de ingreso, de edad y de riesgo. Se da normalmente en el marco del aseguramiento mediante cotizaciones obligatorias o con cargo al presupuesto nacional. El principio de solidaridad que hace efectiva la universalidad del aseguramiento permite tomar en cuenta diferentes aspectos que no son adecuadamente encarados por los sistemas de precios. Entre esos aspectos están: que el individuo no debe cubrir la totalidad de los costos vinculados con su estructura actual de riesgos; que es preciso proteger contra riesgos relacionados con bienes que no tienen un buen sustituto de mercado (por ejemplo, la buena salud); que los precios de mercado no reflejan los costos sociales de oportunidad ni las externalidades del consumo privado y las dimensiones de bien público que este consumo pudiera tener; que hay que encarar el subconsumo asociado a bajos ingresos o al alto riesgo individual, en cuyo caso no se tiene acceso al aseguramiento, aunque exista el mercado. Ello permite corregir externalidades, dado que no sólo se be- neficia del aseguramiento la persona que adquiere una póliza, sino también la sociedad que se beneficia de las externalidades en diversos planos, tales como contar con una población sana, sufrir menos convulsiones sociales, etc.

El aseguramiento social basado en principios de solidaridad permite velar por la eficiencia en la asignación de los recursos, el financiamiento y la provisión, es decir, por la eficiencia para alcanzar objetivos tanto microeconómicos como sociales, y por la equidad (CEPAL, 2000).

Vimos ya que cuando el seguro es voluntario, generalmente el principio de equivalencia conduce a exclusiones, y que las condiciones de un seguro privado no regulado llevan inevitablemente a exclusiones explícitas (por ejemplo, de quienes sufren enfermedades crónicas o congénitas) o implican elevadas primas, deducibles o copagos que representan barreras de entrada.

Por el contrario, los seguros obligatorios, al incluir y retener personas de bajo riesgo, permiten operar con una lógica distinta a la del seguro privado y lograr una diferenciación de riesgo estable. El seguro social puede estar en manos de aseguradores privados; su financiamiento puede provenir de primas obligatorias de trabajadores y empleadores o únicamente de los trabajadores, o bien de impuestos generales; pero en ambas formas su lógica difiere sustancialmente de la del seguro privado, pues rompe la identidad entre prima y riesgo individual y establece en términos más genéricos la cobertura de riesgos, con lo cual pueden incluirse algunos no cubiertos normalmente por los seguros individuales (Barr, 1993, pp. 123-128 y 308). Por lo general, los seguros obligatorios operan con una perspectiva de largo plazo, ya que al establecer garantías generales y no garantías según subgrupos de riesgo, los individuos no son reclasificados en caso de que sus riesgos se incrementen (Arrow, 1963, p. 904).

La diferenciación estable de riesgos, que tiene efectos evidentes en la equidad, también los tiene en la eficiencia. Los fenómenos de selección adversa reducen esta última y en casos extremos pueden conducir a la liquidación de aseguradoras, la denominada death spiral (Cutler y Zeckhauser, 2000, pp. 606-625; Cutler, 2002, pp. 83-86).

Desde la perspectiva individual, los subsidios son dinámicos, ya que a lo largo de la vida los individuos van a proveer o a recibir subsidios según las variaciones de su nivel de riesgo. La equivalencia entre el precio del seguro y el grado de riesgo se establece entonces a escala del sistema y no de la prima individual, y 
se puede dar en el marco de combinaciones públicoprivadas muy diversas.

La magnitud y la profundidad del riesgo social y económico de la región ponen en entredicho la capacidad fiscal para encarar los retos en materia de manejo del riesgo social. Los instrumentos redistributivos amplían la capacidad de financiamiento; en ese sentido, la diversificación estable del riesgo en los mecanismos de aseguramiento y la solidaridad del financiamiento obligatorio contribuyen a ampliar la capacidad de financiamiento.

Para quienes, por su condición de pobreza, no pueden costear con sus propios recursos el acceso a los servicios y protecciones sociales, el financiamiento solidario mediante el presupuesto público garantiza que la solidaridad no interfiera con la solidez financiera de las funciones de ahorro y aseguramiento realizadas por las instituciones vinculadas con esos servicios.

Por otra parte, la transformación de riesgos idiosincrásicos en riesgos catastróficos también alerta sobre la necesidad de consolidar políticas universales y de financiamiento solidario en materia de salud en la región. Debido a la avanzada etapa de transición epidemiológica en que ésta se halla, los desafíos provienen de las enfermedades crónicas y degenerativas, por sus altos costos y la necesidad de consolidar políticas preventivas frente a ellas. Esos desafíos deben ser encarados tanto en el ámbito del financiamiento como de la constitución de sistemas de salud cuyos prestadores conformen redes de referencia eficientes, en diversas combinaciones público-privadas, según sea el caso.

En la transición epidemiológica polarizada de la región son los pobres los que reúnen altas tasas de morbilidad y mortalidad relacionadas con enfermedades tanto pretransicionales como postransicionales. Pero los riesgos idiosincrásicos de salud pueden devenir en catastróficos también para sectores de buenos ingresos, por el alto costo de algunas enfermedades crónicas y degenerativas; esto pone de relieve la importancia de la diversificación del riesgo, la solidaridad y la regulación de las exclusiones. Por ello, si bien las inmunizaciones, las campañas de salud pública y la prevención vinculada a la salud materno-infantil son elementos indispensables en el sector salud, la prevención no puede constituir el foco de largo plazo de los esfuerzos, ni la preocupación por los seguros contra riesgos catastróficos es válida únicamente cuando estos riesgos afectan a los pobres, a diferencia de lo que plantea el Banco Mundial (2000).

Un aspecto importante de los mercados de aseguramiento son las asimetrías de información. La infor- mación necesaria para efectuar una elección racional de un producto, considerando a la vez su naturaleza, su calidad y su precio, muchas veces no puede utilizarse aunque esté disponible, porque es compleja y, por lo tanto, no es bien comprendida. Hay limitaciones de conocimiento, tiempo, criterio o poder, o bien vínculos con consideraciones de otro tipo, que inciden en la decisión. Y el poder y el conocimiento, en general, están estrechamente asociados con la condición socioeconómica (Barr, 1993, p. 296). En circunstancias de incertidumbre, la información se transforma en una mercancía, concentrada en quienes pueden obtener mayores beneficios de ella y pueden pagarla (Arrow, 1963, p. 946).

Ante las complejidades del mercado del aseguramiento, por lo tanto, es aventurado hacer afirmaciones con el grado de generalización de la siguiente: "La diferencia crítica entre un seguro de mercado y un autoseguro es que el primero utiliza la mancomunación para esparcir transversalmente el riesgo entre los individuos" (De Ferranti, Perry y otros, 2000, p. 38). Y en el mismo sentido, resulta confusa la siguiente analogía: "Bajo una interpretación más bien estricta, los homólogos en política pública del aseguramiento individual y del problema de autoprotección son el aseguramiento social (acciones gubernamentales destinadas a aumentar el aseguramiento de mercado y el autoaseguramiento) y la protección social (acciones gubernamentales para aumentar la autoprotección)" (ibid.). ${ }^{11}$

En los sistemas de protección social, el principio de solidaridad del financiamiento y la cotización obligatoria resultan fundamentales, porque amplían los recursos, hacen más estable y equitativa la diversificación de riesgos y permiten subsidios cruzados. Asimismo, establecen un sentido de responsabilidad ciudadana hacia las necesidades de los demás, ${ }^{12}$ en un sistema de aseguramiento y de protección social que al atenuar los riesgos y elevar el bienestar y la certidumbre promuevan conjuntamente la cohesión social, los derechos ciudadanos y la competitividad internacional.

\section{Costos fiscales de la selección del riesgo y del aseguramiento no solidario}

En la polémica pro mercado, muchas veces se establecen relaciones espurias entre la privatización de los

\footnotetext{
11 Traducción propia de las citas en este párrafo.

${ }^{12}$ Lo cual requiere a la vez establecer mecanismos para encarar las diversas conductas de riesgo moral.
} 
sistemas de bienestar y sus efectos positivos en las finanzas públicas, al postular que éstas se verían liberadas del cumplimiento de obligaciones que se asocian al Estado de bienestar. El panorama de la privatización y de la interacción entre aseguramiento de mercado y responsabilidades fiscales, sin embargo, resulta mucho más complejo cuando se analizan las experiencias más radicales de la región.

Desestimar el principio de solidaridad y los sistemas de aseguramiento obligatorio con alta mancomunidad de riesgos y promover el aseguramiento individual sin regular la selección adversa han acarreado importantes costos fiscales y han profundizado la desigualdad en la región. Esto se ilustra muy bien en la actual discusión en Chile sobre un fondo solidario de salud que supere la dualidad sui generis de un sistema de salud alimentado por contribuciones obligatorias que permiten optar por las prestaciones del sector público o del privado, pero que a pesar de su carácter obligatorio, se rige por una lógica dual. El sector público opera con el principio de solidaridad, en tanto que en el sector privado las prestaciones y precios de los planes individuales se ajustan anualmente al riesgo del asegurado, de acuerdo con su sexo, edad y estado de salud. En ese marco, desprovisto de barreras de acceso, el sector público es el instrumento de reaseguro de las instituciones de salud previsional (ISAPRE), que son privadas.

También en Chile tuvo lugar una reforma del sistema de pensiones. El sistema actual, privado, es de contribuciones definidas de capitalización individual, sin ningún componente solidario entre los contribuyentes. Tras dos décadas, evidencia problemas para consolidar su cobertura de la población. Los trabajadores de menores ingresos tienen una mayor propensión a permanecer fuera del sistema previsional. El financiamiento de la transición desde el sistema previo ha representado un gran esfuerzo fiscal. Los costos de operación del sistema nuevo son altos, y aunque éste ha contribuido a impulsar el mercado de capitales, su efecto directo sobre la inversión productiva parece modesto. Debido tanto a la proporción de la fuerza de trabajo empleada en actividades con cobertura discontinua como a los episodios de desempleo y subempleo, es de prever que una parte importante de los afiliados terminará calificando para pensiones asistenciales o mínimas a cargo del Estado. La diferenciación por sexo en los cálculos actuariales de las pensiones se traduce en menores pensiones para las mujeres, lo que repercute en los aportes fiscales subsidiarios (Uthoff, 2001, pp. 35-36; Arenas de Mesa, 2000).

\section{IV}

\section{La propuesta de manejo del riesgo social y su significado para la región}

En el marco de reflexión sobre el riesgo económico y social de la región y sobre los mercados de aseguramiento adquiere relevancia la propuesta de manejo del riesgo social para América Latina, postulada al iniciarse el milenio, ya que articula una determinada visión sobre políticas de aseguramiento con propuestas globales sobre política social. ${ }^{13}$ Aunque su influencia en el diseño de políticas públicas pueda verse limitada por el relativo hermetismo de su terminología, es pertinente analizar esa propuesta debido a sus pretensiones paradigmáticas, no sólo respecto de políticas de aseguramien-

13 El análisis considera fundamentalmente seis documentos: Holzmann y Jorgensen (2000), Banco Mundial (2000 y 2001), y Holzmann (2001). En De Ferranti, Perry y otros (2000) se retoman, en un contexto más amplio, planteamientos análogos. to, sino también respecto del combate contra la pobreza y la delimitación de lo público, que entronizan una responsabilidad social mínima para enfrentar la inseguridad económica. A diferencia de la focalización reduccionista nacida al socaire del ajuste estructural, ${ }^{14}$

\footnotetext{
${ }^{14}$ La focalización reduccionista cobró vigor en el decenio de 1980, cuando organismos como el Banco Mundial, en el marco de propuestas privatizadoras de las políticas sociales y que constreñían la solidaridad de su financiamiento, abogaron por concentrar el gasto público social en los grupos más vulnerables mediante programas focalizados, y por desmantelar los servicios universales, evaluados negativamente como un todo mediante un giro analítico que extrapoló la regresividad de programas como los de pensiones a la generalidad de los programas universales. Se articuló una perspectiva global sobre política social: en tanto que la provisión universal era muy costosa e ineficiente, la focalización sí permitiría a los gobiernos reducir la pobreza con más eficacia y menor costo. En
} 
atribuye mayor importancia a las causas de la pobreza y recurre a una terminología propia del ámbito del aseguramiento.

\section{Una delimitación taxativa de la política social}

El análisis del manejo del riesgo social apunta certeramente a que todas las personas son vulnerables a múltiples riesgos de diverso origen, e interrelaciona el riesgo, la exposición al riesgo y la vulnerabilidad. Constituyen riesgo los eventos que pueden dañar el bienestar y que son inciertos en cuanto a su temporalidad o a la magnitud del daño que pueden causar. La exposición es la probabilidad de que un riesgo ocurra. La vulnerabilidad mide la resistencia a un choque, la probabilidad de que éste se traduzca en una declinación del bienestar que es ante todo función de la dotación de activos de los hogares, de los mecanismos de aseguramiento, y de la severidad y frecuencia de la perturbación (Banco Mundial, 2000, p. 2). La protección social es definida como las intervenciones públicas que ayudan a los individuos, los hogares y comunidades en el manejo del riesgo y que apoyan a los más pobres; ellas deben establecer relaciones de refuerzo mutuo con las áreas de educación y salud, en torno al desarrollo de capital humano (Banco Mundial, 2000, p. 31).

Partiendo del tema del riesgo y del aseguramiento, se formula una propuesta global de política social que articula tres planteamientos fundamentales, y que propone una combinación público-privada cuyas delimitaciones y carácter le son funcionales: las responsabilidades del Estado en materia de bienestar social se circunscriben al combate contra la pobreza; se establece el aseguramiento contra los riesgos como una responsabilidad individual, y se desestima en lo fundamental la solidaridad en la diversificación de riesgos.

En esos términos, el aseguramiento individual en el mercado, la provisión de servicios para los pobres mediante redes de protección y la focalización contrapuesta a la universalidad, conforman una estrategia de

cuanto a la morfología sectorial, se promovió fortalecer la atención primaria en salud y la educación primaria en detrimento de los otros niveles. Y, last but not least, el énfasis en el asistencialismo, que debía amortiguar el impacto de los programas de ajuste, desplazó el interés desde las causas de la pobreza, tema que había estado presente en el decenio de 1970, hacia los síntomas de la pobreza. El carácter polémico y radical de esta perspectiva condujo a discusiones, incluso en el Banco Mundial - fundamentalmente a nivel técnico-, y la visión global sobre política social propia de ella se ha visto erosionada por consideraciones de muy diversa índole, formuladas incluso en el seno del propio Banco Mundial y de otros organismos (Sojo, 1990 y 1999). política social que dispone una responsabilidad pública mínima en materia de protección social, deposita el financiamiento y la prestación de los demás servicios relacionados con el bienestar social en manos privadas, y reitera la desestimación del principio de solidaridad del financiamiento.

De allí la analogía que se puede establecer con las propuestas reduccionistas de focalización propugnadas a partir del decenio de 1980, las que desde el tema de la pobreza planteaban un paradigma semejante en materia de política social.

\section{Pobreza, riesgo y política social}

Más que ayudar a enfrentar riesgos, se propone que las políticas busquen reducirlos y mitigarlos. Los pobres son más vulnerables, porque están más expuestos y tienen poco acceso a activos y pocas dotaciones, en términos de capacidades y recursos, para administrarlos. Por lo mismo, ellos tendrían aversión al riesgo, ${ }^{15}$ y pocas posibilidades de diversificar riesgos, de involucrarse en actividades de alta rentabilidad y de participar en arreglos formales e informales adecuados. Además, sus mecanismos de autoprotección son caros e ineficientes, reducen y lesionan su frágil capital humano y conducen hacia una pobreza crónica con efectos negativos de largo plazo e intergeneracionales (Banco Mundial, 2000, pp. ii, iii, 6, 17, 20, 26 y 27).

Por lo tanto, a diferencia de las propuestas de focalización reduccionistas propias de los decenios de 1980 y 1990, que se centraban en los síntomas antes que en las causas de la pobreza, este planteamiento alude claramente a las causas.

Sin embargo, hay una continuidad en lo que se refiere a la acción del Estado en materia de bienestar social. Para crear activos humanos, físicos, naturales y financieros para los pobres, se propone incrementar el gasto social en servicios básicos y establecer garantías de acceso, de calidad, de elección y de seguimiento respecto de los servicios (Banco Mundial, 2000, pp. 8, $15,19,32,34,38$ y 40). Pero los pobres se conciben casi como el grupo objetivo de la política social y, a su vez, la acción del Estado se considera sinónimo de redes de protección (safety nets), entendidas no necesariamente como una red social amplia, sino como un

\footnotetext{
15 Esta idea de que los pobres tengan aversión al riesgo como rasgo específico, resulta confusa. Sobre todo porque en la teoría sobre aseguramiento, justamente el hecho de que las personas en general tengan aversión al riesgo es una de las bases fundamentales para que el aseguramiento tenga sentido.
} 
sistema modular de programas, flexible según los patrones específicos de riesgo. Este sistema complementa los arreglos existentes en una mezcla adecuada de proveedores públicos y privados, y abarca esquemas e instrumentos - como fondos sociales, microseguros, seguro de salud, pensiones, seguro de desempleo y programas de asistencia social- para apoyar tanto el consumo inmediato como la acumulación de activos físicos, sociales y humanos que permitan salir de la pobreza.

Las redes de protección deben establecerse antes de que haya crisis o conmociones, y deben ser permanentes para contribuir a prevenir y a enfrentar riesgos, ya sea reduciéndolos o mitigándolos. También son pertinentes mecanismos para apoyar a quienes están en riesgo de caer en la pobreza, evitar que sufran daños irreversibles y ampliar el apoyo político a programas de estabilización y reformas (Banco Mundial, 2000, pp. $40,135,147,166,169$ у 170).

En cuanto a América Latina, resalta en la propuesta la visión excesivamente positiva de los fondos sociales, considerados como "productos bien sometidos a prueba que se pueden ofrecer a quienes hacen políticas" y que han tenido resultados positivos en términos de focalización, impacto, ventajas comparativas y costo. Se estima que han empezado a examinar las causas de la pobreza y no sólo las consecuencias del ajuste estructural, e incluso se sobredimensiona su impacto, al afirmar que han prevalecido en la región (Banco Mundial, 2000, pp. iii, vi, 14 y 15).

Tal opinión sobre los fondos sociales contrasta en buena medida con lo surgido de la interesante revisión realizada recientemente por el propio Banco Mundial, que cuestiona, circunscribe o matiza características de los fondos que desde el decenio de 1980 fueron esgrimidas como sus presuntas ventajas, y propone modificar las orientaciones de la política del Banco en la materia. En esta revisión se desestima la contraposición de políticas orientadas a la oferta o a la demanda y se da importancia a la consideración de las variables institucionales específicas de cada país, en aras de lograr una inserción de fondos estratégica, y no cortoplacista o aislada, que sea complementaria con las instituciones pertinentes y también sustentable, y que no desplace a la reforma de políticas (Banco Mundial, 2002, pp. 45-50).

Lo expresado en dicha revisión coincide en buena medida con sendas críticas que se habían realizado a la trayectoria efectiva de estos organismos: sus recursos escasos, menores que los de los esquemas asistencialistas tradicionales o de los programas previos al ajuste; sus acotadas replicabilidad y continuidad, debido a los altos salarios pagados a sus gestores, a la buena calidad de su infraestructura administrativa y a la relativa dependencia de un alto financiamiento externo; su baja cobertura, por la cual tiene escaso impacto en la reducción de la pobreza, la creación de empleo y la redistribución del ingreso; su inadecuada vinculación con las políticas sectoriales; sus dificultades de focalización; los problemas de sustentabilidad de los proyectos emprendidos; las desigualdades derivadas del subsidio a la demanda; la baja calidad del empleo creado -que es temporal, de baja calificación, con remuneraciones bajo la línea de pobreza y fuertes sesgos de género-, y la escasa difusión de los cambios organizativos logrados (Godoy y Rangel, 1998; Cornia, 1999).

Por otra parte, la propuesta de manejo social del riesgo imputa asimismo características muy positivas a los seguros informales de riesgo, llamados también microseguros, subestimando las asimetrías de información en el marco de relaciones y liderazgos no formalizados, y las restricciones impuestas por la propensión al consumo presente causada por la necesidad de los pobres (Holzmann y Jorgensen, 2000, p. 10; Banco Mundial, 2000, pp. vi, 25, 26 y 31).

$\mathrm{Al}$ sobreestimar los presuntos rasgos positivos de los mecanismos informales de aseguramiento, que en lo fundamental son una evidencia de la desprotección social, es posible que no se haga adecuado hincapié en la necesidad de transitar hacia el aseguramiento formal y que se desestiman las condiciones que lo harían posible de manera gradual. ${ }^{16}$

Cabe recordar que en los países desarrollados las instituciones modernas de protección social se originaron parcialmente en instituciones de aseguramiento mutuo, en cooperativas de ahorro para consumo y vivienda, en sindicatos y mutuales de pensiones (Norton, Conway y Foster, 2001). Y sin ir más lejos, las aseguradoras de salud denominadas obras sociales y mutuales en Argentina y Uruguay, de carácter cuasi público, tuvieron un origen semejante.

\footnotetext{
${ }^{16}$ En el caso inglés, por ejemplo, estas instituciones de la sociedad civil, fundamentales en la construcción del capital social durante la industrialización, configuraron una ideología y cultura organizativa que contribuyó al surgimiento del movimiento laborista, del gobierno representativo y del Estado de bienestar que asumió un amplio espectro de funciones de protección social (Norton, Conway y Foster, 2001, p. 44).
} 


\section{El aseguramiento de mercado}

Se estima que los arreglos públicos en los países en desarrollo son relativamente escasos y de cobertura limitada, debido fundamentalmente a causas fiscales y al bajo empleo formal; que los mercados de seguros son casi inexistentes, por problemas de información asimétrica y restricciones para hacer cumplir los contratos, y que la proporción del empleo informal evidencia la importancia de los arreglos informales en materia de riesgo (Holzmann y Jorgensen, 2000, p. 10; Banco Mundial, 2000, pp. 25 y 31).

América Latina y el Caribe se considera una región heterogénea en cuanto al ingreso y la existencia de mecanismos de manejo del riesgo social, y se plantea que en muchos de sus países los mecanismos públicos han sido del tipo de los establecidos en países de la Organización de Cooperación y Desarrollo Económicos (OCDE); la propuesta para esta región reúne varios componentes. En primer lugar, se destaca la importancia de los mecanismos informales de mitigación del riesgo, dado que la fuerza de trabajo que se halla en el sector formal aún es, en promedio, sólo cercana a la mitad de la fuerza de trabajo total. En seguida se propone que estos países hagan menos hincapié en los mecanismos de mitigación de riesgo provistos por el gobierno y las tasas de contribución a los programas de seguridad social que ello implica, así como en las provisiones informales, y que enfaticen y promuevan instrumentos de mitigación de riesgos basadas en el mercado. Es decir, deben alejarse de los extremos izquierdo y derecho de la matriz de manejo del riesgo social (cuadro 3), y hacer también "movimientos horizontales" en ella, para atender más a la reducción de riesgos. También deben fortalecer las redes de protección para situaciones potenciales de crisis (Banco Mundial, 2001, p. 70).

Los postulados son tributarios de las propuestas de aseguramiento centradas en el individuo, que acotan nítidamente el ámbito para la acción pública y para la diversificación de riesgos, como se expresa en el siguiente análisis: "Con una aproximación centrada en el individuo, la necesidad de que el gobierno actúe surge únicamente donde los mercados fallan, y la formulación de política social se basa en principios minimalistas y no ad hoc; el papel del gobierno aquí —impelido por preocupaciones de eficiencia en un ambiente de riesgoes el de ampliar los mercados; es decir, facilitar el aseguramiento y la autoprotección mediante instrumentos, si los mercados no existen (por ejemplo, en el caso del seguro de desempleo), o mediante intervenciones para mejorar la calidad de los instrumentos si los individuos usan distintos modos de aseguramiento" (De Ferranti, Perry y otros, 2000, p. 42). ${ }^{17}$

En tales términos, las acciones de gobierno destinadas a ampliar la diversificación de riesgos, denominadas de aseguramiento social, son básicamente políticas para incrementar el aseguramiento del mercado; en consecuencia, las acciones de aseguramiento social que se avalan (por ejemplo, el seguro por discapacidad) son muy acotadas. ${ }^{18}$ Los esquemas obligatorios sin diversificación de riesgo deben así acrecentar el autoaseguramiento, y las políticas de protección social que facilitan la adquisición de capital humano deben aumentar la autoprotección (De Ferranti, Perry y otros, 2000, p. 42).

En cuanto a la diversificación de riesgos en el mercado de aseguramiento, la participación obligatoria en mancomunaciones de riesgo se acepta como positiva para evitar problemas de selección adversa, pero se afirma que sólo es pertinente cuando no existen mecanismos de mercado o éstos colapsan o son disfuncionales (Banco Mundial, 2000, p. 25; Holzmann y Jorgensen, 2000, p. 10).

Tal diversificación de riesgo se desalienta y se contrapone con el seguro de mercado. Finalmente, el riesgo se enfrenta mejor mediante una combinación de seguro de mercado, autoaseguramiento y autoprotección. Quienes hacen políticas deben reconocer esto, y notar especialmente que el mercado de aseguramiento con diversificación de riesgo es altamente propenso a fallar. La mejor solución suele ser la de corregir y complementar el mercado, más que sustituirlo. La regulación inteligente es esencial para tal fin, sea en los mercados de trabajo o financieros o en los servicios de salud (De Ferranti, Perry y otros, 2000, p. 123).

Este reduccionismo en política social -que circunscribe la responsabilidad pública en materia de protección social a políticas focalizadas en los pobres mediante redes de protección, y que en este caso promueve el aseguramiento individual, desestimando el principio de solidaridad en un régimen de aseguramiento social o aceptando sólo en el margen mancomunaciones de riesgo mediante contribuciones obligatorias- reitera la postergación de políticas sociales vigorosas y de una adecuada inversión social que hagan viable una

\footnotetext{
17 Traducción propia de la cita en este párrafo.

18 Hay que reconocer, sin embargo, que en De Ferranti, Perry y otros (2000) se considera el seguro de desempleo; esto tendría connotaciones fiscales muy grandes en América Latina, debido a lo endeble de los mercados laborales y a la volatilidad.
} 
CUADRO 3

Estrategias y disposiciones para el manejo del riesgo social: matriz y ejemplos

\begin{tabular}{|c|c|c|c|}
\hline Disposiciones y estrategias & Informales & Basadas en el mercado & Públicas \\
\hline Reducción de riesgo & $\begin{array}{l}\text { - Menor producción riesgosa } \\
\text { - Migración } \\
\text { - Prácticas adecuadas de } \\
\text { alimentación y destete } \\
\text { - Participación en actividades } \\
\text { de higiene y otras que } \\
\text { previenen enfermedades }\end{array}$ & $\begin{array}{l}\text { - Capacitación en el trabajo } \\
\text { - Capacitación básica en } \\
\text { finanzas de mercado } \\
\text { - Estándares de trabajo de las } \\
\text { empresas y del mercado }\end{array}$ & $\begin{array}{l}\text { - Estándares públicos de } \\
\text { trabajo } \\
\text { - Capacitación previa } \\
\text { - Políticas de mercado laboral } \\
\text { - Intervenciones en trabajo } \\
\text { infantil } \\
\text { - Políticas sobre discapacitados } \\
\text { - Buenas políticas } \\
\text { macroeconómicas } \\
\text { - Prevención del SIDA y otras } \\
\text { enfermedades } \\
\text { - Legislación para eliminar } \\
\text { desigualdades de derechos de } \\
\text { propiedad, matrimonio y } \\
\text { acceso a mercados laborales }\end{array}$ \\
\hline
\end{tabular}

Mitigación del riesgo

Cartera

$\begin{array}{ll}\text { Aseguramiento } & \text { - Matrimonio, familia } \\ & \text { - Arreglos comunitarios } \\ & \text { - Tenencia de acciones } \\ & \text { - Trabajo } \\ & \\ & \\ \text { Enfrentamiento de riesgos } & \text { Venta de acciones reales } \\ & \text { - Migración } \\ & \text { - Crédito de vecinos } \\ & \text { - Transferencias intracomunita- } \\ & \text { rias, caridad } \\ & \text { - Trabajo infantil } \\ & \text { - Desahorro en capital humano }\end{array}$

- Inversión en múltiples activos financieros

- Microfinanzas

- Pensiones de vejez

- Seguros de accidentes, discapacidad y otros seguros personales

- Seguros por daños a cosechas, incendio y otros

- Venta de activos financieros - Créditos bancarios
- Sistemas de pensiones multipilares (con más de una fuente de financiamiento)

- Transferencias de activos

- Protección de derechos de propiedad (énfasis en mujeres)

- Apoyo para extender mercado financiero a los pobres

- Aseguramiento obligatorio y provisto, de desempleo, vejez, discapacidad, etc.

\footnotetext{
- Transferencias, asistencia social

- Subsidios

- Trabajos de infraestructura públicos
}

Fuente: Elaboración del Banco Mundial (2001), cuadro 2.2, p. 15.

mejor inserción de América Latina y el Caribe en el mundo globalizado, con mayor bienestar e integración social. Si bien los fondos de inversión social o los microseguros son adecuados en determinadas circuns- tancias, la reducción de la política pública a tales instrumentos no permite encarar en toda su magnitud y profundidad el riesgo económico y social vigente y los desafíos del desarrollo económico y social. 


\section{V}

\section{El desafío del financiamiento}

Como lo muestra una variedad de estudios, en los países de la región es impostergable iniciar o profundizar, según el caso, las reformas de los sistemas de protección social en diversos ámbitos: protección contra riesgos vinculados a la mayor precariedad del mercado de trabajo; aumento de la cobertura de los sistemas de pensiones; forma de encarar las dificultades del Estado para cumplir con sus responsabilidades fiscales en materia de pensiones mínimas, básicas o asistenciales; manejo del riesgo en los fondos de pensiones ante crisis financieras, y manejo de los propios fondos; mejora de la baja cobertura, eficiencia y equidad de los programas para enfrentar el desempleo; e incremento de la cobertura en salud y de la calidad de las prestaciones. Asimismo, si se promueve la competencia en el aseguramiento y las prestaciones de salud, se debe fortalecer la capacidad regulatoria en materia de selección de riesgo, subsidios cruzados del sector público al sector privado, hipertrofia de la intermediación financiera y aseguradora, y altos costos de transacción cuando se ha establecido separación de funciones para constituir cuasi mercados.

En términos de riesgo social, la gran heterogeneidad del mercado laboral y las vastas dimensiones del sector informal plantean demandas especiales a la política social, a la vez que limitan la base impositiva para financiar la política social mediante contribuciones obligatorias o con cargo al presupuesto fiscal.

En ese sentido, son cruciales aquellas políticas que tratan de reducir eventuales efectos de sustitución (trade-offs) en el financiamiento. Por ejemplo, en cuanto a la contribución de diversos grupos de ingreso, o bien las que encaran efectos de sustitución intertemporales en el financiamiento que está a cargo del Estado. Como veremos en seguida, al actuar sobre ellos los mecanismos de financiación se proponen diversos objetivos. ${ }^{19}$

Para enfrentar la complejidad de los mercados de aseguramiento, como ya se vio, son fundamentales el financiamiento solidario y la diversificación de riesgos. Además, tal como en algunos sistemas de pensiones

\footnotetext{
${ }^{19}$ Los planteamientos sobre financiación que se hacen en adelante se basan en diálogos con Rebeca Grynspan sobre ideas formuladas por ella.
}

que combinan diversas formas de contribución denominadas pilares, debe establecerse como condición para el aporte obligatorio individual que haya un aporte solidario, y se puede contemplar la opción de contribuciones individuales optativas, orientadas a retener a los sectores de mayores ingresos, a disminuir la evasión y elusión y a incentivar el ahorro voluntario de los tramos de ingreso que superan el techo impositivo de las contribuciones obligatorias.

Postergar reformas que significan incrementar el gasto es una opción que involucra una valoración del gasto presente en relación con el gasto futuro y que expresa opciones intertemporales en las cuales, naturalmente, influyen el horizonte temporal de los gobiernos y la alternancia en el poder de las agrupaciones políticas. Postergar la inversión social en el presente apelando a restricciones fiscales puede, de hecho, aumentar sensiblemente las presiones sobre el gasto fiscal futuro.

$\mathrm{Al}$ respecto, cabe considerar, por ejemplo, el caso de quienes por sus bajos ingresos deban recibir en la tercera edad un financiamiento proveniente de los impuestos generales. Puede suponerse, en una perspectiva dinámica y dado el prolongado deterioro de la calidad del empleo, que este contingente será cada vez mayor. Existe la posibilidad de intervenir desde ya para tratar de incluir en el sector contributivo a quienes están excluidos del mercado formal de trabajo, para minimizar el impacto negativo de la dinámica del mercado laboral sobre el financiamiento no contributivo. En ese sentido, desde el punto de vista conceptual y político, es válido preguntarse cuál es el costo de subsidiar la contribución de sectores con capacidad de ahorro insuficiente para pagar la contribución que corresponda a la suma de la contribución del patrono y del obrero, o a la del obrero si no existe la contribución patronal; en este caso, la contribución del trabajador informal debe ascender a un monto que evite crear incentivos espurios para estar en un régimen subsidiado.

El costo de este subsidio debe sopesarse contra el costo fiscal futuro correspondiente a las proyecciones de lo que representarían las pensiones no contributivas en ausencia de dicho subsidio al régimen contributivo. Hay que considerar además los beneficios po- 
tenciales que involucra un aumento del ahorro público y el reconocimiento presente de lo que sería una contingencia postergada. A la vez, se pone sobre el tapete el interrogante sobre la forma de financiar el subsidio: si mediante impuestos específicos o mediante un determinado incremento de la carga fiscal.

Toda opción de política debiera plantearse que no hay sólo una forma de ahorro de los pobres. Por ejemplo, existe una gama de opciones relativas a aseguramientos colectivos, en los cuales las organizaciones de trabajadores suscriben acuerdos con una entidad aseguradora que les garantiza un sistema solidario, diversificación de riesgos y menores costos de transacción y administración. El colectivo paga entonces una cuota media por persona a una entidad aseguradora y se establece una diversificación de riesgo asociada a una determinada cobertura. La relación entre la cuota media y la cuota individual determina el subsidio, pero éste no existe para el grupo como tal.

En cuanto a la universalidad y su financiamiento solidario, el desdeñar ad portas esta posibilidad, o analizar la solidaridad sólo a escalas excesivamente micro, escamotea el análisis de aquellas condiciones históricas de nuestra propia región que han permitido avanzar gradualmente hacia ese horizonte en países tan disímiles como Brasil, Colombia y Costa Rica.

\section{Bibliografía}

Arenas de Mesa, A. (2000): Cobertura previsional en Chile: lecciones y desafíos del sistema de pensiones administrado por el sector privado, serie Financiamiento del desarrollo, $\mathrm{N}^{\circ} 105$, LC/L.1457-P, Santiago de Chile, CEPAL, diciembre. Publicación de las Naciones Unidas, $\mathrm{N}^{\mathrm{o}}$ de venta: S.00.II.G.137.

Arhin-Tenkorang, D. (2001): Health Insurance for the Informal Sector in Africa: Design Features, Risk Protection, and Resource Mobilization, CMH Working Papers Series, No WG3:1, Cambridge, Massachusetts, Grupo de Trabajo 3 de la Comisión sobre Macroeconomía y Salud de la Organización Mundial de la Salud (OMS), septiembre (http://www.cmhealth.org/ docs/wg3_paper1.pdf).

Arrow, K. (1963): Uncertainty and the welfare economics of medical care, The American Economic Review, vol. 53, No 5, Nashville, Tennessee, American Economic Association, diciembre.

(2000): Insurance, risk and resource allocation, en G. Dionne y S.E. Harrington (comps.), Foundations of Insurance Economics. Readings in Economics and Finance, Boston, Kluwer Academic Publishers.

Banco Mundial (2000): Social Protection Sector Strategy: from Safety Net to Spring Board. Draft Final Report, exclusivamente para uso oficial, Washington, D.C., agosto.

(2001): Social Protection Sector Strategy: from Safety Net to Spring Board, Washington, D.C., enero.

(2002): Social Funds. A Review of World Bank Experience, Washington, D.C, Departamento de Evaluación de Operaciones, febrero.

Barr, N. (1993): The Economics of the Welfare State, segunda edición, Stanford, California, Stanford University Press.

Baulch, B. y J. Hoddinott (2000): Economic mobility and poverty dynamics in developing countries, The Journal of Development Studies, vol. 36, N 6 , Londres, Frank Cass Publishers, agosto.

Beccaria, L. (2001): Inestabilidad laboral y de ingresos en Argentina, Estudios del trabajo, No 21, Buenos Aires, Asociación argentina de especialistas en estudios del trabajo (ASET).

Belli, P. (2001): How adverse selection affects the health insurance market, Policy Research Working Paper, № 2574, Washington, D.C., Banco Mundial (http://econ.worldbank.org).

CEPAL (Comisión Económica para América Latina y el Caribe) (2000): Equidad, desarrollo y ciudadanía (Versión definitiva), LC/G.2071/Rev.1-P, Santiago de Chile. Publicación de las Naciones Unidas, $\mathrm{N}^{\mathrm{o}}$ de venta: S.00.II.G.81.

Cook, P. y D. Graham (2000): The demand for insurance and protection. The case of irreplaceable commodities, en G.
Dionne y S.E. Harrington (comps.), Foundations of Insurance Economics. Readings in Economics and Finance, Boston, Kluwer Academic Publishers.

Cornia, A. (1999): Social funds in stabilisation and adjustment programmes, Research for Action, $\mathrm{N}^{\circ} 48$, Helsinki, Universidad de Naciones Unidas/Instituto Mundial de Investigaciones de Economía del Desarrollo (UNU/WIDER).

Cutler, D. (2002): Health Care and the Public Sector, NBER Research Paper, No 8802, Cambridge, Massachusetts, National Bureau of Economic Research (http://www.nber.org/papers/w8802).

Cutler, D. y R. Zeckhauser (2000): The anatomy of health insurance, en A.J. Culyer y J.P. Newhouse, Handbook of Health Economics, vol. 1A, Amsterdam, Elsevier Science Publishers.

De Ferranti, D., G. Perry y otros (2000): Securing Our Future in a Global Economy, Washington, D.C., Banco Mundial, junio, (http://wbln0018.worldbank.org/lac/car_edstrat/secdoclib.nsf). (2002): De los recursos naturales a la economía del conocimiento. Comercio y calidad del empleo, Estudios del Banco Mundial sobre América Latina y el Caribe, Washington, D.C., Banco Mundial.

Deaton, A. (1997): The Analysis of Household Surveys. A Microeconomic Approach to Development Policy, Baltimore, The Johns Hopkins University Press.

Dionne, G. y S.E. Harrington (2000): An introduction to insurance economics, en G. Dionne y S.E. Harrington (comps.), Foundations of Insurance Economics. Readings in Economics and Finance, Boston, Kluwer Academic Publishers.

Ehrlich, I. y G. Becker (2000): Market insurance, self-insurance, and self-protection, en G. Dionne y S.E. Harrington (comps.), Foundations of Insurance Economics. Readings in Economics and Finance, Boston, Kluwer Academic Publishers.

Feijóo, M. (2001): Nuevo país, nueva pobreza, Buenos Aires, Fondo de Cultura Económica (FCE).

Gaviria, A. (2001): Household Responses to Adverse Income Shocks in Latin America, IDB Research Department Working Paper, $\mathrm{N}^{\mathrm{o}} 455$, Washington, D.C., Banco Interamericano de Desarrollo (BID), julio.

Godoy, L. y M. Rangel (1998): Nuevas experiencias en política social: los fondos de inversión social en América Latina y el Caribe, Revista Paraguaya de Sociología, № 101, Asunción, Centro Paraguayo de Estudios Sociológicos, enero-abril.

Hirschman, A. (1970): Exit, Voice and Loyalty : Responses to Decline in Firms, Organisations and States, Massachusetts, Harvard University Press. 
Holzmann, R. (2001): Risk and vulnerability: the forward looking role of social protection in a globalizing world, Social Protection Discussion Paper, No 0109, Washington, D.C., Banco Mundial, junio.

Holzmann, R. y S. Jorgensen (2000): Social risk management: a new conceptual framework for social protection and beyond, Social Protection Discussion Paper, $\mathrm{N}^{\circ}$ 0006, Washington, D.C., Banco Mundial, febrero.

Kessler, G. (s/f): L'expérience de paupérisation de la classe moyenne argentine. Artículo basado en la tesis de doctorado en sociología "Le processus de paupérisation de la classe moyenne argentine (1976-1995)", presentada en 1998 en la École des Hautes Etudes en Sciences Sociales, París, inédito.

(s/f): "Redefinición del mundo social en tiempos de cambio. Una tipología para la experiencia del empobrecimiento", Buenos Aires, inédito.

(s/f): "Capital cultural, ciudadanía y estrategia en los servicios públicos. El caso de los nuevos pobres en la Argentina", Buenos Aires, borrador para discusión.

Minujin, A. y N. López (1993): Sobre pobres y vulnerables: el caso argentino, Documento de trabajo, $\mathrm{N}^{\circ} 18$, Buenos Aires, Fondo de las Naciones Unidas para la Infancia (UNICEF).

Moore, M. (2001): Creating Public Value. Strategic Management in Government, Cambridge, Massachusetts, Harvard University Press.

Musgrave, R.A. (1985): A brief history of fiscal doctrine, en A.J. Auerbach y M. Feldstein, Handbook of Public Economics, vol. 1, Amsterdam, Elsevier Science Publishers

Norton, A., T. Conway y M. Foster (2001): Social Protection Concepts and Approaches: Implications for Policy and Practice in International Development, Londres, Centre for Aid and Public Expenditure, Instituto de Desarrollo de Ultramar, febrero.

Oakland, W. (1991): Theory of public goods, en A. Auerbach y M. Feldstein, Handbook of Public Economics, vol. 2, Amsterdam, Elsevier Science Publishers.
Ocampo, J.A. (2001): Retomar la agenda del desarrollo, LC/L.1503, Santiago de Chile, CEPAL, marzo.

OIT (Organización Internacional del Trabajo) (2000): Informe sobre el trabajo en el mundo, 2000. La seguridad de los ingresos y la protección social en un mundo en plena transformación, Ginebra.

Rodríguez, J. (2003): La fecundidad alta en América Latina y el Caribe: un riesgo en transición, ponencia presentada en el Seminario "La fecundidad alta en América Latina y el Caribe: transición o revolución", Santiago de Chile, CEPAL, junio, inédito.

Rodrik, D. (2001): ¿Por qué hay tanta inseguridad económica en América Latina?, Revista de la CEPAL, No 73, LC/G.2130-P, Santiago de Chile, abril.

Sauma, P. y M. Sánchez (2003): Énfasis exportador en Costa Rica: efectos en el crecimiento, la desigualdad y la pobreza, febrero, inédito.

Sojo, A. (1990): Naturaleza y selectividad de la política social, Revista de la CEPAL, $\mathrm{N}^{\circ}$ 41, LC/G.1631-P, Santiago de Chile, agosto.

(1999): La política social en la encrucijada: opciones o disyuntivas, en J. Carpio e I. Novacovsky (comps.), De igual a igual. El desafío del Estado ante los nuevos problemas sociales, Buenos Aires, Fondo de Cultura Económica (FCE)/ Sistema de Información, Monitoreo y Evaluación de Programas Sociales (SIEMPRO)/Facultad Latinoamericana de Ciencias Sociales (FLACSO).

Uthoff, A. (2001): La reforma del sistema de pensiones en Chile: desafíos pendientes, serie Financiamiento del desarrollo, $N^{\circ}$ 112, LC/L.1575-P, Santiago de Chile, julio. Publicación de las Naciones Unidas, $\mathrm{N}^{\circ}$ de venta: S.01.II.G.118.

Van de Ven, W. y R. Ellis (2000): Risk adjustment in competitive health plan markets, en A.J. Culyer y J.P. Newhouse, Handbook of Health Economics, vol. 1A, Amsterdam, Elsevier Science Publishers. 